\title{
Miguel de Castro, Discurso de mi tragedia y vida, ed. Francisco Estévez, Huelva, Universidad de Huelva, Etiópicas. Revista de letras renacentistas, Anejo núm. 8, 2021, 206 pp. ISBN: 978-84- 18628-51-1 / ISSN: 1698-689X
}

\section{Nicolás Mateos Frühbeck}

http://orcid.org/0000-0001-7810-0851

Universidad Autónoma de Madrid ESPAÑA

nicomat97@hotmail.com

[Hipogrifo, (issn: 2328-1308), 9.2, 2021, pp. 1137-1139]

Recibido: 18-10-2021 / Aceptado: 09-11-2021

DOI: http://dx.doi.org/10.13035/H.2021.09.02.78

Hacía falta una nueva edición del Discurso de mi tragedia y vida de Miguel de Castro, que por fin ha salido a la luz a manos de Francisco Estévez, uno de los mayores conocedores y estudiosos de la autobiografía militar de los siglos XVI y XVII en España. Se trata de una labor que no solamente da cuenta de una obra no demasiado considerada por la crítica, sino de todo el interés que han recobrado las autobiografías de los dichos siglos y que se refleja en la reedición de obras como esta y muchas otras en los últimos años.

Hasta el momento, tan solo se contaba con unas pocas ediciones de este manuscrito autobiográfico, cuyos textos, en casi todos los casos, son idénticos al que Antonio Paz y Meliá fijó en 1900 en su edición Vida del soldado Español Miguel de Castro (1593-1617) y en el que también se ha apoyado Estévez para fijar el de la suya. Apenas existen estudios que se centren única y exclusivamente en esta autobiografía, entre los que destaca el capítulo que Levisi le dedica en su mítica monografía Autobiografías del Siglo de Oro, aunque en ella buena parte de su trabajo gire en torno a criticar la obra y sus carencias estilísticas, y los pocos artículos que se han ido publicando al respecto en las últimas décadas. 
Por ello, un trabajo como el realizado por Francisco Estévez resulta, como mínimo, necesario, especialmente para aquellos interesados en el ámbito autobiográfico que tan poca atención ha recibido desde una perspectiva analítico-literaria. Gracias a la labor de Estévez, en lo tocante al trabajo ecdótico, el lector se encuentra con una serie de correcciones que facilitan y agilizan la lectura de la autobiografía de cara al a la edición de Paz y Meliá, que, en palabras del filólogo, «presentaba carencias a las que se trata de dar solución aquí» (p. 19). A esto se le suma, además, la labor en torno a las notas a pie de página, tanto las explicativas como las meramente crítico-textuales, que dinamizan, una vez más, la comprensión de una obra de esta dimensión, cuyo texto está plagado de referencias a ciudades, empresas y personajes de la corte, que, en la gran mayoría de casos, poseen una pequeña nota explicativa que contextualiza y, asimismo, prueba la veracidad de lo que se está narrando.

Como no podía ser de otra manera, al Discurso de Miguel de Castro le precede un breve trabajo que sirve como introducción, y que analiza tanto la situación actual del tema autobiográfico como su relación con el resto de obras de la misma índole, como es el caso de las célebres autobiografías de Contreras o del duque de Estrada, más estudiadas por parte de la crítica. Una vez más se discute el grado de veracidad que, en principio, se presupone en un texto autobiográfico; sin embargo, como bien señala el editor, se trata, en este caso, de una «pregunta ya acaso imposible de responder» (p. 9), así como la razón que debió mover a un personaje tan interesante como Miguel de Castro a plantearse la redacción de su propia vida $y$, consecuentemente, el sentido que aporta a los episodios que decide incluir en este texto y que configuran la estructura del mismo. Las dudas que surgen tras la lectura de esta obra son varias, y permiten proponer posibles explicaciones para algunas de ellas. Estévez, quien hace especial hincapié en el hecho de que se trate de una de las autobiografías más atrevidas de la época por su crudeza a la hora de referirse a los episodios de intimidad, esto es, a sus múltiples relaciones sexuales y amoríos con una infinidad de diferentes mujeres, también se atreve a desarrollar posibles razones por las que el texto carece de un final que dé respuesta al «centro de gravedad de la autobiografía, su indomable ímpetu amoroso». Para el editor «parece verosímil pensar que el proyecto quedó trunco, lo cual explicaría la falta de orden, las repeticiones [...], acaso también las amnesias selectivas en fechas y podrían haber aclarado el destinatario y el sentido final» (p. 13).

Se deben destacar también las relaciones que el propio Estévez establece entre esta obra, hasta el momento poco estudiada, y algunos de los principios clave sobre la teoría del "yo" y la propia teoría de la autobiografía, dado que, para el editor, "la tradición crítica ha interpretado estos apasionantes relatos en lo que trasiegan de realidad y la potencial ficción de su prosa en clave picaresca» (p. 10), en lugar de haber considerado desde el primer momento la autodiégesis y el «discurso del yo» (p. 10) como verdaderos elementos de interés, que es realmente lo que diferencia al Discurso del resto de autobiografías militares de estos siglos. En cualquier caso, este tipo de propuestas abre una serie de posibilidades para futuros estudios sobre este texto y muestra algunas de las múltiples dudas que pueden tener lugar tras la lectura de una autobiografía de esta clase. 
En lo referente al propio Discurso, como ya avisa Estévez en su introducción, Castro no escatima a la hora de presentar y de describir minuciosamente sus vicisitudes sexuales y las consecuentes desgracias que dichos sucesos acarrean en su vida militar y en su posible ascendencia en la Corte. Su poca timidez y la minuciosidad de las narraciones sobre estos episodios abarcan la gran mayoría de la obra, lo que, como ya mencionamos antes, convierte este Discurso en un texto a tener en cuenta, al menos de cara a la comprensión psicológica y las costumbres de los militares -y, en general, de la sociedad- de principios del siglo XVII.

Además, esta obra permite poner en duda algunas de las tesis de los teóricos de la autobiografía, como es el caso de Lejeune, quienes prefieren no tener en cuenta las autobiografías escritas antes de las Confesiones de Rousseau, por no tratarse de una "historia de la personalidad", lo que no parece tan evidente si se toman en consideración textos como el que escribe Miguel de Castro alrededor de 1612.

Dicho esto, a modo de conclusión, la revisión de las anteriores ediciones por parte de Estévez, así como su valioso trabajo introductorio reavivan el interés de una obra como el Discurso de mi tragedia y vida de Miguel de Castro en vistas a posibles investigaciones futuras, tanto de esta obra como del resto de textos que conforman las autobiografías del siglo XVI y XVII. La labor del editor resulta encomiable; sin embargo, el hecho de que este texto haya merecido una reedición puede dar a lugar a posibles revisiones teórico-literarias sobre la autobiografía y las tesis por las que se han delimitado en el tiempo la gran mayoría de estudios sobre el tema; razón por la que, además, se han visto apartadas todas estas autobiografías del ámbito hispánico que, en las últimas décadas, han comenzado a cobrar un merecido interés por parte de la crítica. 